\title{
Acoustic radiation force impulse elastography for evaluating renal parenchymal stiffness in children
}

\author{
Fuat Ozkan • Mehmet Sait Menzilcioglu • \\ Mahmut Duymus • Sema Yildiz • Serhat Avcu
}

Received: 5 August 2014 / Accepted: 22 August 2014 / Published online: 25 September 2014

(C) Springer-Verlag Berlin Heidelberg 2014

Sir,

We read the article "Acoustic radiation force impulse elastography for detection of renal damage in children" by Goya et al. [1], with great interest. A precise identification of sampled renal segments and their orientation according to the US beam is obligatory when performing renal ultrasound elastography [2], because Gennisson et al. [3] showed the effects of anisotropy in vivo in pig kidneys with high mean variation due to complex intrarenal architecture [3]. Later Bruno et al. [4] in evaluating the kidneys in children with vesicoureteric reflux stressed the importance of orienting the region of interest with its main axis lying as parallel as possible to the main axis of the pyramids to reduce the effect of anisotropy. However, Goya et al. [1] did not discuss this technical aspect in their article [1]. In addition, Bruno et al. [4] emphasised the importance of constant compression exerted on the transducer when making shear wave velocity measurements. This followed from the findings of Syversveen et al. [5], who reported that acoustic radiation force impulse elasticity estimates may, in general, vary with applied transducer force. This technique detail also was not mentioned by Goya et al. [1]. Studies have shown that variability of measurements in the renal parenchyma is a real issue, whichever elastography technique is used [2]. Therefore meticulous attention to quality control in image acquisition and measurements is essential for implementation of this technique, especially in children.
We also think it is essential to calculate shear wave velocity cut-off values with receiver operator characteristics curve analyses, using dimercaptosuccinic acid scintigraphy severity score and vesicoureteral reflux grade as reference standards, before clinical implementation.

Conflicts of interest None

\section{References}

1. Goya C, Hamidi C, Ece A et al (2014) Acoustic radiation force impulse (ARFI) elastography for detection of renal damage in children. Pediatr Radiol [Epub ahead of print]. doi:10.1007/s00247-0143072-3

2. Grenier N, Gennisson JL, Cornelis F et al (2013) Renal ultrasound elastography. Diagn Interv Imaging 94:545-550

3. Gennisson JL, Grenier N, Combe C et al (2012) Supersonic shear wave elastography of in vivo pig kidney: influence of blood pressure, urinary pressure and tissue anisotropy. Ultrasound Med Biol 38:15591567

4. Bruno C, Caliari G, Zaffanello M et al (2013) Acoustic radiation force impulse (ARFI) in the evaluation of the renal parenchymal stiffness in paediatric patients with vesicoureteral reflux: preliminary results. Eur Radiol 23:3477-3484

5. Syversveen T, Midtvedt K, Berstad AE et al (2012) Tissue elasticity estimated by acoustic radiation force impulse quantification depends on the applied transducer force: an experimental study in kidney transplant patients. Eur Radiol 22:2130-2137

F. Ozkan $(\bowtie) \cdot$ M. S. Menzilcioglu $\cdot$ M. Duymus $\cdot$ S. Yildiz

S. Avcu

Department of Radiology, Gazi University, School of Medicine,

Ankara, Turkey

e-mail: drfozkan@yahoo.com 